\title{
Factors Influencing Follow-up to Newborn Hearing Screening for Infants who are Hard-of-Hearing
}

\author{
Lenore Holte, Ph.D. ${ }^{a, b}$, Elizabeth Walker, Ph.D. ${ }^{a}$, Jacob Oleson, Ph.D.c ${ }^{c}$ Meredith Spratford, \\ AuD. ${ }^{d}$, Mary Pat Moeller, Ph.D. ${ }^{d}$, Patricia Roush, AuD. ${ }^{e}$, J. Bruce Tomblin, Ph.D. ${ }^{a}$, and Hua \\ Ou, Ph.D. ${ }^{\mathrm{a}, \mathrm{c}}$ \\ aDepartment of Communication Sciences and Disorders, University of lowa, lowa City, IA \\ bDepartment of Pediatrics, University of lowa, lowa City, IA \\ 'Department of Biostatistics, University of lowa, lowa City, IA \\ dBoystown National Research Hospital, Omaha, NE \\ eDepartment of Otolaryngology, University of North Carolina, Chapel Hill, NC
}

\begin{abstract}
Purpose-To document the epidemiological characteristics of a group of hard-of-hearing children, to identify individual predictor variables for timely follow-up after a failed newborn hearing screen, and to identify barriers to follow-up encountered by families.
\end{abstract}

\begin{abstract}
Method-An accelerated longitudinal design was used to investigate outcomes for children who are hard-of-hearing in a large multicenter study. The current study involves a subgroup of 193 of children with hearing loss who did not pass the newborn hearing screen. Available records were used to capture ages of confirmation of hearing loss, hearing aid fitting and entry into early intervention. Linear regression models were used to investigate relationships among individual predictor variables and age at each follow-up benchmark.

Results-Of several predictor variables, only higher levels of maternal education were significantly associated with earlier confirmation of hearing loss and fitting of hearing aids. Severity of hearing loss was not. No variables were significantly associated with age of entry into early intervention. Each recommended benchmark was met by a majority of children, but only one-third met all of the benchmarks within the recommended time frame.
\end{abstract}

Conclusions-Results suggest that underserved communities need extra support in navigating steps that follow failed newborn hearing screening.

\section{Keywords}

hearing loss; universal newborn hearing screening

Copyright 2012 by American Speech-Language-Hearing Association.

Corresponding author: Lenore Holte. Ph.D. 148 CDD, 100 Hawkins Drive, University of Iowa, Iowa City, IA 52242, Ph: 319-356-1168, Fax: 319-356-8284, lenore-holte@uiowa.edu.

The authors have no financial relationships relevant to this article to disclose.

Publisher's Disclaimer: This is an author-produced manuscript that has been peer reviewed and accepted for publication in the American Journal of Audiology $(A J A)$. As the "Papers in Press" version of the manuscript, it has not yet undergone copyediting, proofreading, or other quality controls associated with final published articles. As the publisher and copyright holder, the American Speech-Language-Hearing Association (ASHA) disclaims any liability resulting from use of inaccurate or misleading data or information contained herein. Further, the authors have disclosed that permission has been obtained for use of any copyrighted material and that, if applicable, conflicts of interest have been noted in the manuscript. 


\section{INTRODUCTION}

Delayed identification of permanent childhood hearing loss (HL), which occurs in 1 to 3 per thousand live births (Finitzo, Albright, \& O'Neal, 1998; Van Naarden, Decoufle, \& Caldwell, 1999), is regarded as a major public health concern. Children with mild-to-severe HL (i.e., hard of hearing; HH) represent a unique and historically underserved group (Davis, 1977; Davis, Elfenbein, Schum, \& Bentler, 1986; Davis, Shepard, Stelmachowicz, \& Gorga, 1981; Elfenbein, Hardin-Jones, \& Davis, 1994; Mace, Wallace, Whan, \& Stelmachowicz, 1991; Moeller, Donaghy, Beauchaine, Lewis, \& Stelmachowicz, 1996; Moeller, McCleary, Putman, Tyler-Krings, Hoover, \& Stelmachowicz, 2010; Moeller, Tomblin, YoshinagaItano, Connor, \& Jerger, 2007). Prior to Universal Newborn Hearing Screening (UNHS), it was rare for these children to be identified before 2 years of age, and many were identified even later (Halpin, Smith, Widen, \& Chertoff, 2010; Ruben, 1997; Sininger, Martinez, Eisenberg, Christensen, Grimes, \& Hu, 2009; Spivak, Sokol, Auerbach, \& Gershkovich, 2009; Stein, Jabaley, Spitz, Stoakley, \& McGee, 1990; Yoshinaga-Itano, Sedey, Coulter, \& Mehl, 1998).

Early intervention is effective in preventing or minimizing the negative impact of HL on speech and language development (Calderon \& Naidu, 1999; Kennedy et al., 2006; Moeller, 2000). However, it is likely that early identification will result in developmental advantages for children only if the process is linked to timely and effective interventions. The American Academy of Pediatrics (AAP, 2010) and the Joint Committee on Infant Hearing (JCIH, 2007) have recommended "1-3-6" benchmarks for follow up: (1) complete newborn hearing screening (NHS) before 1 month of age, (2) diagnose HL before 3 months, and (3) enroll those identified with HL in early intervention before 6 months. According to the Centers for Disease Control and Prevention (CDC) in 2006, $91.2 \%$ of newborns were screened for hearing loss and $2.1 \%$ did not pass that screen. Of those who did not pass the screen, $29.9 \%$ were found to have normal hearing and $5.8 \%$ were found to have hearing loss, but no diagnosis could be documented in $64.2 \%$ of the babies who did not pass the newborn hearing screen (Gaffney, Green, \& Gaffney, 2010). By 2009, the latest year for which data are available (U.S. Centers for Disease Control, 2011), national statistics improved: Ninetyeight percent of eligible newborns were screened and $1.6 \%$ did not pass. Of those who did not pass the screen, $39.0 \%$ were found to have normal hearing, $8.9 \%$ were diagnosed with hearing loss and $45.1 \%$ were lost to follow up or documentation. Advances in consistent data tracking and surveillance systems are partially responsible for these improvements. Even when progress through the EHDI process is timely, there exist wide variations among service providers in pediatric audiologic test batteries and appointment wait times (Munoz, Nelson, Goldgewicht, \& Odell, 2011). This discouraging rate of loss to follow-up or documentation, along with variability in service provision, indicates that despite widespread UNHS, challenges remain to ensure that all children with prelingual HL can take advantage of the benefits of timely diagnosis, hearing aid fitting and entry into early intervention.

Unfortunately, challenges remain for many families in accomplishing recommended followup steps. Identified barriers to follow-up include: 1) limited access to audiologists with pediatric expertise, 2) appointment wait times, 3) the presence of medical co-morbidities, and 4) the presence of unilateral or mild HL (Coplan, 1987; Dalzell et al., 2000; Folsom, Widen, Vohr, Cone-Wesson, Gorga, Sininger, \& Norton, 2000; Harrison \& Roush, 1996; Moeller, Eiten, White, \& Shisler, 2006; Moeller, White, \& Shisler, 2006). Additionally, families of HH infants may have difficulty understanding the need to follow-up on a failed screening, given that they may observe the baby responding to loud sounds in the environment. 
Several investigations have addressed factors related to loss to follow-up or delays in follow up. These include the presence of other medical conditions and the presence of unilateral or mild HL (Folsom et al., 2000; Dalzell et al., 2000). Severity of hearing loss can impact timeliness of follow-up: Prior to the era of universal newborn hearing screening, the age at which congenital HL was diagnosed and intervention was begun was often inversely related to the severity of HL (Coplan, 1987; Mace et al., 1991; Harrison \& Roush, 1996). It is unknown whether this is still true. A recent survey study of state EHDI programs indicated the primary barriers to linking families to follow-up included lack of service-system capacity, lack of provider knowledge, challenges in obtaining services and information gaps (Shulman, Besculides, Saltzman, Ireys, White, \& Forsman, 2010). Difficulties in system capacity included unreliable screening equipment, a shortage of sufficiently trained pediatric audiologists, inadequate early intervention services and lack of family support programs. Although providers have been found to be generally very supportive of NHS and follow-up (Goedert, Moeller, \& White, 2011; Moeller, Eiten, et al., 2006; Moeller, White, et al., 2006), Shulman et al. found that many screening programs do not have standardized protocols, that some physicians take a "wait-and-see" attitude toward follow-up and that many providers lack specific knowledge about early intervention or family supports in the local area. In addition, families face challenges with respect to transportation for specialized services and third party payment for professional services, hearing aids and other amplification (Limb, McManus, Fox, White, \& Forsman, 2010). Finally, information gaps exist when data management and tracking systems are not accessible to providers or when there exists poor communication among providers. Results of surveys of state EHDI coordinators and service providers are useful, but little data exist regarding families' perceptions of barriers in the process.

There is a need to determine if prompt follow-up occurs after a failed NHS and if advancements in early identification result in the expected developmental advantages for $\mathrm{HH}$ children. To address these needs, the National Institutes of Health (NIH) funded a collaborative research team to investigate the speech, language, academic, psychosocial and family outcomes of HH children. The Outcomes of Children with Hearing Loss (OCHL) study is a five-year, multi-center investigation designed to characterize the developmental, behavioral and familial outcomes of $\mathrm{HH}$ children and to explore how variations in child and family factors and intervention characteristics relate to functional outcomes.

The present paper provides a general description of the design and methods of the OCHL study and the demographic characteristics of the study population. A primary goal of the current study is to document timeliness of follow-up steps for a subgroup of children who did not pass newborn hearing screening. Specifically, the study was designed to address the following questions:

1. How do family and child-specific factors such as socio-economic status (SES) and severity of HL affect timely diagnosis and follow-up?

2. How consistently are $\mathrm{HH}$ children receiving appropriate care and follow-up within the best-practice 1-3-6 timeline?

3. What reasons are given by families for delays between various steps in the EHDI process?

\section{METHODS OCHL Study Methods}

Test batteries were developed to examine: 1) family and community factors (e.g., SES, race, ethnicity, service access, parental education), 2) child factors (e.g., gender, severity and type 
of HL, etiology), 3) child outcomes (e.g., receptive and expressive language, speech perception and production, psychosocial development, academic abilities), and 4) intervention characteristics (e.g., audiological, therapeutic and educational). Developmentally-appropriate test batteries included normative-based tests, speech and language elicitation tasks, language sampling, and parent and service provider questionnaires. At each visit, children completed a comprehensive pediatric audiological evaluation. Specific measures and age intervals employed in the OCHL study are listed in Appendix A. This overall approach supports the goal of determining how family and child factors interact with intervention features to influence outcomes.

An accelerated longitudinal design (see Fig 1) maximized the amount of developmental and cross-sectional data that could be collected in a relatively short period of time. Children ranging in age from 6 months to 6 years 11 months were enrolled and followed prospectively on an annual basis for at least three visits from the age at entry. Those enrolled as infants or toddlers were seen every six months until 24 months of age and annually thereafter. Retrospective historical, medical, audiological, and educational data were collected to supplement the prospective data. Children were recruited and seen in the home states of the three research teams (Iowa, Nebraska, North Carolina), as well as in cooperative neighboring states (Kansas, Minnesota, Illinois, Missouri, and Virginia). State EHDI coordinators, audiologists, early intervention specialists, and educators assisted with recruiting $\mathrm{HH}$ children. Children with normal hearing $(\mathrm{NH})$ were recruited from databases of past research participants, fliers in community centers and daycares or advertisements in newsletters, and word of mouth. A screening interview was conducted over the telephone to ensure basic criteria for candidacy were met. Approval for the study was obtained by the Institution Review Boards of each participating research site.

Inclusion criteria for the $\mathrm{HH}$ group included: a) permanent bilateral $\mathrm{HL}$ of any type (sensorineural, mixed, conductive), b) better ear pure tone average (PTA) $(500,1000500$, 2000 , and $4000 \mathrm{~Hz}$ ) between 25 and $75 \mathrm{~dB} \mathrm{HL}, \mathrm{c}$ ) entry ages between 6 months and 6 years, 11 months of age, d) no known significant sensory or developmental disorders, and e) at least one primary caregiver who speaks English in the home. Recruited participants in the OCHL study to date include $292 \mathrm{HH}$ children and $115 \mathrm{NH}$ peers who were matched on age and home background.

At the initial visit, parents completed an intake interview that documented several benchmark steps toward the diagnosis of $\mathrm{HL}$ and the receipt of early intervention including age at a) first diagnostic audiologic evaluation, 2) confirmation of HL, 3) hearing aid fitting, and 4) entry into early intervention. Parents also provided an explanation for any delays that occurred between steps.

At the initial visit and each subsequent visit, the $\mathrm{HH}$ child received an on-site comprehensive audiologic evaluation and the child's hearing aids were evaluated. When possible, the device use time was captured as a digital measure from the hearing aids. If audiometric results were not obtained due to child behavior or time constraints, a recent audiogram from the child's audiologist was obtained with parental permission. A receptive and expressive speech and language evaluation was also performed and measures of academic skills and psychosocial behavior were obtained, if age-appropriate. Parents completed questionnaires regarding their child's development, behavior and temperament, and hearing aid use.

\section{Current Study Methods}

The current statistical analyses focused on a subgroup of $193 \mathrm{HH}$ participants with congenital hearing loss who did not pass the NHS. The $99 \mathrm{HH}$ children who were excluded 
from these analyses did not have a documented NHS or passed the screen and thus likely had delayed onset hearing loss. For the subgroup of children who did not pass NHS ( $\mathrm{n}=$ 193), we explored the potential effects of child and family variables on timeliness of followup steps. Linear regression models investigated the relationships among the independent predictor variables (gender, site of testing, SES, and severity of HL) and each of the dependent variables (ages at each follow-up benchmark). Because none of the dependent variables were normally distributed, they were normalized by modeling the natural log of each of these variables.

\section{RESULTS}

The demographic characteristics of all HH participants recruited to date in the OCHL study are presented in Table 1. The distribution of better ear PTA for all participants is presented in Figure 2. The highest percentage of participants fell in the range of moderate HL. Eighteen participants had permanent conductive HL and the remainder had sensorineural HL. Table 1 also includes the demographic characteristics of the 193 children who are the primary focus of the current study.

For participants with congenital HL, the wide ranges of values of the dependent variables in this group who failed the newborn screen were striking: Ages of first diagnostic evaluation ranged from 0.25 to 60 months, ages of confirmation of HL ranged from 0.5 to 70 months, ages of entry into early intervention ranged from 0.25 to 57 months (some with long delays did not have age of entry into intervention reported) and ages of hearing aid fitting ranged from 1.5 to 72 months. Biological mother's education was significantly correlated with biological father's education and income group $(p<0.0001)$. To avoid the problem of multicollinearity between predictor variables and because more data were available for mother's education level than the other two SES variables, only biological mothers' education was used in the regression model as an indicator of SES. Of the independent variables, only mother's education was found to be significantly related to the ages of first diagnostic audiologic evaluation $(p=0.0123)$, HL confirmation $(p=0.0013)$ and hearing aid fit $(p=0.0445)$. None of the predictor variables were significantly related to the age at which the child entered early intervention. Similarly, none were significantly related to the time that elapsed between the EHDI milestones of HL confirmation, HA fitting, and entry into early intervention.

Figure 3 shows the average ages (in months) of first diagnostic evaluation, confirmation of HL, hearing aid fit, and entry into early intervention by mother's educational level. One difference is worth noting: The mean age of confirmation of HL for infants whose mothers had graduate degrees was more than seven months earlier than for those whose mothers had a high school diploma or less. Although all of these children were screened by 1 month of age, infants of mothers with the least education were later to receive follow up at every stage.

The proportion of children who met the national 1-3-6 goals, as outlined in the latest JCIH (2007) statement, is shown in Figure 4. Despite the fact that all of these participants failed a physiological hearing screen in the first month of life, only $83 \%$ had a diagnostic Auditory Brainstem Response (ABR) test by 3 months of age and only $64 \%$ had a confirmed diagnosis by 3 months of age. Hearing aids were fit on $66 \%$ of these children within one month of confirmation of $\mathrm{HL}$ and $75 \%$ were enrolled in early intervention by 6 months of age. Only $32 \%$ of these participants met all three of the JCIH benchmarks on time.

Parent interviews provided explanations for delays between steps in the EHDI process; these are summarized in Table 2 . The first analysis examined delays between a failed NHS and 
the first diagnostic evaluation. Seventy-three participants (38\%) had a delay of more than 2 months and 67 of these provided a reason. The most common reason was multiple rescreens, which ranged in number from 2 to 10 following the referred newborn screen and accounted for delays up to 9 months in getting a diagnostic ABR. Other families experienced delays because of transient middle ear problems and some of these were reportedly told by physicians there was no need to get a diagnostic ABR. Six families could not get a timely appointment for a diagnostic ABR. Three families were reportedly told the ABR could not be completed until the baby was old enough to be sedated. Several others were delayed because of additional health conditions and appointments following a complicated newborn admission.

Next, delays between the first diagnostic audiologic evaluation and confirmation of HL were explored. One hundred nine (56\%) children had HL confirmed at the first diagnostic ABR evaluation. Thirty-two (17\%), however, had a delay of more than 2 months and 24 of these had a delay of more than 3 months between the first diagnostic audiologic evaluation and confirmation of HL. Twenty-three provided reasons. Fifteen infants underwent multiple ABR evaluations before a diagnosis was confirmed. Reasons for multiple ABRs included lack of sleep by the infant, equipment problems experienced by the audiologist, or multiple re-testing to confirm that the HL was not conductive and temporary. These are certainly valid reasons for multiple ABR tests, but they can lead to delays in confirmation of $\mathrm{HL}$ and HA fitting. Five families reported that the initial ABR was normal or near normal and a subsequent ABR indicated HL.

We also examined delays between HL confirmation and hearing aid fitting. The JCIH (2007) goals recommend no more than a month between confirmation of HL and hearing aid fitting. Sixty-six participants (34\%) had a delay of more than 1 month to hearing aid fitting and 62 of these provided a reason. Eleven of these children did not have hearing aids recommended initially and some of these recommendations were justified: Two had mild HL which progressed in degree and 4 had unaidable unilateral HL which later progressed to bilateral. Two were told to wait until 6 months of age for amplification even though the HL was confirmed much earlier. In 12 other cases, families made the decision not to pursue amplification because their child was responding to sound and it was difficult for them to believe the diagnosis of HL. Four other families had delays due to difficulty obtaining funding and 10 had difficulty obtaining an appointment for hearing aid fitting. Other delays were caused by the misperception of physicians that a behavioral audiogram was necessary before diagnosis was reliable and hearing aids could be fit.

Finally, we examined delays between confirmation of HL and entry into early intervention services. Twenty-one children (11\%) had delays of more than 3 months between confirmation of HL and the initiation of early intervention services; nine of these reported a reason. Three families chose not to start intervention until the child was older (10, 13 and 15 months respectively). In two other cases, HL started out as unilateral and early intervention was not provided until bilateral HL developed. Two families reported that it took an extended period of time for service providers to schedule a visit. In another case the family had difficulty believing there was a HL, while another experienced delays due to multiple medical appointments.

\section{DISCUSSION}

In an effort to determine the timeliness of diagnosis and intervention for a cohort of $193 \mathrm{HH}$ children, we studied family and child-specific factors and their impact on age of diagnosis and intervention. We also examined specific reasons cited by families for delays in 
diagnosis and intervention. Finally, we compared the age of diagnosis and intervention for the study cohort to the 1-3-6 benchmarks recommended by AAP (2010) and JCIH (2007).

For the first question, family and child-specific factors, we found that higher SES, as measured by mothers' educational level, was associated with earlier ages of first diagnostic evaluation, HL confirmation, and hearing aid fitting. The mean age of confirmation of HL for infants whose mothers had graduate degrees was more than seven months earlier than for mothers whose highest level of education was at or below high school, despite the fact that NHS is provided as a public health initiative and all infants in this subgroup were screened for HL by one month of age. Mother's education was not, however, related to age of enrollment in early intervention (EI) services. This may be a consequence of federal legislation that requires prompt referral following diagnosis of HL to determine eligibility for early intervention services.

A factor that could limit the generalizability of the present results is the representativeness of the educational level of mothers in our study sample. According to the 2010 United States Census, $44 \%$ of the population has a high school degree or less, $28 \%$ have attended some college, $18 \%$ have a college degree and $10 \%$ have graduate or professional degrees. The OCHL sample of children who did not pass the newborn hearing screen comes from families with higher educational degrees than the general population where $18 \%, 34 \%, 26 \%$, and $22 \%$ of children come from households where the mother's education level are in the above categories, respectively. Given the importance of this variable as a predictor of timely follow-up, it is likely that compliance with benchmarks in our more highly educated group is an overestimate of compliance in the general population.

A child-specific factor of interest was degree of HL and whether it was associated with age of diagnosis and intervention. Our findings, which did not show a relationship between degree of HL and age of diagnosis and intervention, were similar to those of a recent study (Spivak, et al., 2009) and are in contrast to earlier studies prior to the implementation of UNHS that found later identification of infants with milder degrees of HL (Coplan, 1987; Harrison \& Roush, 1996; Mace, et al., 1991). This newer evidence implies that UNHS ensures timely follow-up even for milder degrees of HL.

Another aim was to study the specific reasons cited by families for delays in diagnosis and intervention. The reasons included variability in audiological test protocols, excessive wait times for appointments, delays associated with medical co-morbidities, and presence of mild or unilateral HL. These findings were similar to earlier reports (Coplan, 1987; Harrison \& Roush, 1996; Mace, et al., 1991; Prieve et al., 2000). The most frequently cited reason for delay in diagnosis of $\mathrm{HL}$ in the current study was multiple rescreenings and diagnostic tests by physicians and audiologists. Reports of multiple rescreenings are of particular concern considering that JCIH as well as EHDI guidelines in most states recommend referral for a comprehensive diagnostic evaluation with ABR following only one additional screening failure. Although repeated ABRs are sometimes necessary for a firm diagnosis, several families reported that incomplete ABR studies were conducted at one center before a comprehensive study was eventually completed at another center. This necessitated the use of sedation or general anesthesia due to the older age of the child, further delaying the diagnosis. Because there is variability between ABR thresholds and behavioral hearing thresholds, the diagnostic ABR represents the first step in an ongoing process to quantify the $\mathrm{HL}$ for hearing aid fitting. Hearing aid selection for infants below a developmental age of 6 months should rely on physiologic measures (JCIH, 2007), but behavioral follow-up testing when a child is older remains essential in optimizing audibility of speech. 
Two additional issues resulted in delays in diagnosis and interventions in the current study group: 1) otitis media at the time of follow-up and 2) subjective observations of the child responding to sound. Parents reported delays in every step of the EHDI process when a healthcare professional attributed a failed screen or diagnosed HL to temporary middle ear effusion, without acknowledging that an underlying sensorineural HL may be present. Additionally, both professionals and parents delayed follow-up in some cases because a child responded to sound in the environment. Many parents with HH infants require additional counseling in order to appreciate the importance of proactive steps to encourage the child's communicative development.

These reported obstacles provide unique insights into opportunities for improvement in EHDI system capacity, public awareness, professional continuing education, and clinical practices. To avoid multiple rescreenings and multiple diagnostic tests, there is a need for knowledgeable pediatric audiologists to partner with primary care providers to provide definitive diagnostic care. There is also a need for greater access to audiological services, because difficulty obtaining an appointment was a recurring theme among those who experienced delays along the 1-3-6 timeline. Priority scheduling should be allotted to children who are $\mathrm{HH}$ for these benchmark appointments.

Educational materials about the NHS and follow-up process should be designed for, and distributed to, parents of children who do not pass the newborn hearing screening so that implications of HL are demonstrated clearly and are easily understood. These materials should cater to principles of healthcare literacy and family-centered care and emphasize early signs of $\mathrm{HL}$ and the impact of even mild degrees of HL on future developmental outcomes. Beyond public awareness, parents with less formal education (lower SES) may need further support in navigating the EHDI system - ensuring quick linkages with Early Intervention Coordinators and provision of family-to-family supports may help.

Fortunately, many of the children received timely diagnosis and follow-up care consistent with the 1-3-6 benchmark goals; however, approximately two-thirds of children referred from screening did not achieve all three goals by 6 months of age. Families reported a variety of factors related to the child, family, physician, or intervention program that created delays or obstacles to timely and appropriate diagnosis and intervention. Children enrolled in the OCHL study are a diverse group and efforts are made to ensure that families can participate despite apparent barriers. Research studies will carry some bias toward inclusion of children whose families have the resources and inclination to participate, thus the cohort described in this study may not include those who are at risk for the greatest delays in diagnosis and intervention. It is important for EHDI programs to develop materials and methods for public awareness campaigns that will be effective in communicating to the most vulnerable populations. The present findings regarding reasons for delays in the EHDI process also indicate that continuing professional education is needed for audiologists and physicians.

In conclusion, results of the present study indicate the following:

1. Many families in the current study accessed care following NHS within recommended time frames. Specific barriers were identified, and these appear to be addressable through improved systems, services and educational efforts.

2. In a group of children who are $\mathrm{HH}$, higher maternal educational levels were significantly associated with earlier confirmation of HL and fitting of amplification. Severity of HL was not. 
3. Public awareness campaigns about NHS and the importance of good hearing for speech and language development must continue to be developed, with particular emphasis on underserved communities.

4. There remains confusion on the part of providers and families about the possibility of HL in infants and toddlers who display awareness of sound. Educational resources and training should address this specific gap in understanding.

\section{Acknowledgments}

The authors would like to thank Richard Arenas and Shana Jacobs for assistance with data collection and manuscript preparation. This publication was made possible by Grant Number R01 DC009560 from NIDCD. Its contents are solely the responsibility of the authors and do not necessarily represent the official views of the NIDCD or NIH.

Funded by the NIH

\section{References}

AAP. National Center for Hearing Assessment and Management (Ncham) and American Academy of Pediatrics (Aap): Early Hearing Detection and Intervention (Edhi) - Guidelines for Pediatric Medical Home Providers. 2010. Retrieved February 2010, from http://www.medicalhomeinfo.org/ downloads/pdfs/EHDIGuidelines.pdf

Calderon R, Naidu S. Further Support of the Benefits of Early Identification and Intervention with Children with Hearing Loss. Volta Review. 1999; 100(5):53-84.

Coplan J. Deafness: Ever Heard of It? Delayed Recognition of Permanent Hearing Loss. Pediatrics. 1987; 79(2):206-213. [PubMed: 2433675]

Dalzell L, Orlando M, MacDonald M, Berg A, Bradley M, Cacace A, Prieve B. The New York State Universal Newborn Hearing Screening Demonstration Project: Ages of Hearing Loss Identification, Hearing Aid Fitting, and Enrollment in Early Intervention. Ear and Hearing. 2000; 21(2):118-130. [PubMed: 10777019]

Davis, JM. Our Forgotten Children: Hard of Hearing Pupils in the Schools. Minneapolis, MN: University of Minnesota; 1977.

Davis JM, Elfenbein J, Schum R, Bentler RA. Effects of Mild and Moderate Hearing Impairments on Language, Educational, and Psychosocial Behavior of Children. Journal of Speech and Hearing Disorders. 1986; 51(1):53-62. [PubMed: 3945060]

Davis JM, Shepard NT, Stelmachowicz PG, Gorga MP. Characteristics of Hearing-Impaired Children in the Public Schools: Part Ii--Psychoeducational Data. Journal of Speech and Hearing Disorders. 1981; 46(2):130-137. [PubMed: 7253589]

Elfenbein JL, Hardin-Jones MA, Davis JM. Oral Communication Skills of Children Who Are Hard of Hearing. Journal of Speech and Hearing Research. 1994; 37(1):216-226. [PubMed: 8170125]

Finitzo T, Albright K, O’Neal J. The Newborn with Hearing Loss: Detection in the Nursery. Pediatrics. 1998; 102(6):1452-1460. [PubMed: 9832584]

Folsom RC, Widen JE, Vohr BR, Cone-Wesson B, Gorga MP, Sininger YS, Norton SJ. Identification of Neonatal Hearing Impairment: Recruitment and Follow-Up. Ear and Hearing. 2000; 21(5):462_ 470. [PubMed: 11059704]

Gaffney M, Green DR, Gaffney C. Newborn Hearing Screening and Follow-Up: Are Children Receiving Recommended Services? Public Health Reports. 2010; 125(2):199-207. [PubMed: 20297746]

Goedert MH, Moeller MP, White KR. Midwives' Knowledge, Attitudes, and Practices Related to Newborn Hearing Screening. Journal of Midwifery \& Women's Health. 2011; 56(2):147-153.

Halpin KS, Smith KY, Widen JE, Chertoff ME. Effects of Universal Newborn Hearing Screening on an Early Intervention Program for Children with Hearing Loss, Birth to 3 Yr of Age. Journal of the American Academy of Audiology. 2010; 21(3):169-175. [PubMed: 20211121] 
Harrison M, Roush J. Age of Suspicion, Identification, and Intervention for Infants and Young Children with Hearing Loss: A National Study. Ear and Hearing. 1996; 17(1):55-62. [PubMed: 8741968]

JCIH. Year 2007 Position Statement: Principles and Guidelines for Early Hearing Detection and Intervention Programs. Pediatrics. 2007; 120(4):898-921. [PubMed: 17908777]

Kennedy CR, McCann DC, Campbell MJ, Law CM, Mullee M, Petrou S, Stevenson J. Language Ability after Early Detection of Permanent Childhood Hearing Impairment. The New England Journal of Medicine. 2006; 354(20):2131-2141. [PubMed: 16707750]

Limb SJ, McManus MA, Fox HB, White KR, Forsman I. Ensuring Financial Access to Hearing Aids for Infants and Young Children. Pediatrics. 2010; 126(Suppl 1):S43-51. [PubMed: 20679323]

Mace AL, Wallace KL, Whan MQ, Stelmachowicz PG. Relevant Factors in the Identification of Hearing Loss. Ear and Hearing. 1991; 12(4):287-293. [PubMed: 1723705]

Moeller MP. Early Intervention and Language Development in Children Who Are Deaf and Hard of Hearing. Pediatrics. 2000; 106(3):E43. [PubMed: 10969127]

Moeller MP, Donaghy KF, Beauchaine KL, Lewis DE, Stelmachowicz PG. Longitudinal Study of Fm System Use in Nonacademic Settings: Effects on Language Development. Ear and Hearing. 1996; 17(1):28-41. [PubMed: 8741965]

Moeller MP, Eiten L, White K, Shisler L. Strategies for Educating Physicians About Newborn Hearing Screening. Journal of the Academy of Rehabilitative Audiology. 2006; 39:11-32. [PubMed: 20871740]

Moeller MP, McCleary E, Putman C, Tyler-Krings A, Hoover B, Stelmachowicz P. Longitudinal Development of Phonology and Morphology in Children with Late-Identified Mild-Moderate Sensorineural Hearing Loss. Ear and Hearing. 2010; 31(5):625-635. [PubMed: 20548239]

Moeller MP, Tomblin JB, Yoshinaga-Itano C, Connor CM, Jerger S. Current State of Knowledge: Language and Literacy of Children with Hearing Impairment. Ear and Hearing. 2007; 28(6):740753. [PubMed: 17982362]

Moeller MP, White KR, Shisler L. Primary Care Physicians' Knowledge, Attitudes, and Practices Related to Newborn Hearing Screening. Pediatrics. 2006; 118(4):1357-1370. [PubMed: 17015524]

Munoz K, Nelson L, Goldgewicht N, Odell D. Early Hearing Detection and Intervention: Diagnostic Hearing Assessment Practices. American Journal of Audiology. 2011; 20(2):123-131. [PubMed: 21764998]

Prieve B, Dalzell L, Berg A, Bradley M, Cacace A, Campbell D, Stevens F. The New York State Universal Newborn Hearing Screening Demonstration Project: Outpatient Outcome Measures. Ear and Hearing. 2000; 21(2):104-117. [PubMed: 10777018]

Ruben RJ. A Time Frame of Critical/Sensitive Periods of Language Development. Acta OtoLaryngologica. 1997; 117(2):202-205. [PubMed: 9105448]

Shulman S, Besculides M, Saltzman A, Ireys H, White KR, Forsman I. Evaluation of the Universal Newborn Hearing Screening and Intervention Program. Pediatrics. 2010; 126(Suppl 1):S19-27. [PubMed: 20679316]

Sininger YS, Martinez A, Eisenberg L, Christensen E, Grimes A, Hu J. Newborn Hearing Screening Speeds Diagnosis and Access to Intervention by 20-25 Months. Journal of the American Academy of Audiology. 2009; 20(1):49-57. [PubMed: 19927682]

Spivak L, Sokol H, Auerbach C, Gershkovich S. Newborn Hearing Screening Follow-Up: Factors Affecting Hearing Aid Fitting by 6 Months of Age. American Journal of Audiology. 2009; 18(1): 24-33. [PubMed: 19029532]

Stein LK, Jabaley T, Spitz R, Stoakley D, McGee T. The Hearing-Impaired Infant: Patterns of Identification and Habilitation Revisited. Ear and Hearing. 1990; 11(3):201-205. [PubMed: 2358130]

U.S. Centers for Disease Control, E. H. D. I. Summary of 2009 National Cdc Edhi Data. 2011. Retrieved from http://www.cdc.gov/ncbddd/hearingloss/2009-Data/ 2009_EHDI_HSFS_Summary_508_OK.pdf 
Van Naarden K, Decoufle P, Caldwell K. Prevalence and Characteristics of Children with Serious Hearing Impairment in Metropolitan Atlanta, 1991-1993. Pediatrics. 1999; 103(3):570-575. [PubMed: 10049958]

Yoshinaga-Itano C, Sedey AL, Coulter DK, Mehl AL. Language of Early- and Later-Identified Children with Hearing Loss. Pediatrics. 1998; 102(5):1161-1171. [PubMed: 9794949]

\section{Appendix}

\begin{tabular}{|c|c|c|}
\hline DOMAINS ASSESSED: & MEASUREMENT INSTRUMENTS: & $\begin{array}{l}\text { AGE AT TEST } \\
\text { (months) }\end{array}$ \\
\hline \multirow[t]{2}{*}{ Presymbolic Communication } & $\begin{array}{l}\text { Communication and Symbolic Behavior Scales: } \\
\text { Temptations }\end{array}$ & 18 \\
\hline & $\begin{array}{l}\text { Communication and Symbolic Behavior Scales } \\
\text { Caregiver Questionnaire }\end{array}$ & 18 \\
\hline Vocal Development Landmarks & $\begin{array}{l}\text { Vocal Development Landmarks (created for } \\
\text { study) }\end{array}$ & $6,12,18$ \\
\hline \multicolumn{3}{|l|}{ LANGUAGE MEASURES } \\
\hline & Spontaneous Language Sample & $36,72,96$ \\
\hline \multirow[t]{5}{*}{ Vocabulary (receptive \& expressive) } & $\begin{array}{l}\text { MacArthur Bates Communicative Development } \\
\text { Inventory (MBCDI) Words \& Gestures ( } 8 \text { to } 18 \\
\text { mos) }\end{array}$ & 12,18 \\
\hline & MBCDI Words \& Sentences (19 to $30 \mathrm{mos}$ ) & 24 \\
\hline & MBCDI Upper Extension (31 mos and up) & 36 \\
\hline & Peabody Picture Vocabulary Test- 4 & $60,84,108$ \\
\hline & $\begin{array}{l}\text { Weschler Abbreviated Scale of Intelligence } \\
\text { (WASI) vocabulary }\end{array}$ & $72,84,96,108$ \\
\hline Verbal Reasoning & Preschool Language Assessment Instrument-2 & 60 \\
\hline \multirow[t]{4}{*}{ Global Rec-Exp Measure } & Mullen Scales of Early Learning & 12,24 \\
\hline & $\begin{array}{l}\text { Comprehensive Assessment of Spoken } \\
\text { Language 3-4 Core }\end{array}$ & 36,48 \\
\hline & $\begin{array}{l}\text { Comprehensive Assessment of Spoken } \\
\text { Language 5-6 Core }\end{array}$ & 72 \\
\hline & $\begin{array}{l}\text { Comprehensive Assess. of Spoken Language } 7- \\
10 \text { Core }\end{array}$ & 96 \\
\hline Narrative & Candy Stealing Story & 84,108 \\
\hline \multirow[t]{2}{*}{ Elicitation of mental state stories } & Explanation of Action Movies & 84,108 \\
\hline & $\begin{array}{l}\text { Theory of Mind measures (Standard False } \\
\text { Belief Tasks) }\end{array}$ & 60,72 \\
\hline \multirow[t]{2}{*}{ Morphology } & $\begin{array}{l}\text { Clinical Evaluation of Language } \\
\text { Fundamentals- } 4 \text { Word Structure }\end{array}$ & 60,84 \\
\hline & $\begin{array}{l}\text { Morphological Elicitation Procedure (created } \\
\text { for study) }\end{array}$ & 36,48 \\
\hline \multicolumn{3}{|l|}{ SPEECH PRODUCTION MEASURES } \\
\hline \multirow[t]{3}{*}{ Speech Production } & Goldman-Fristoe Test of Articulation & $36,60,84,108$ \\
\hline & Open \& Closed Set Test (D. Ertmer) & 24 \\
\hline & $\begin{array}{l}\text { Conditioned Assessment of Speech Perception } \\
\text { and Production P (Ertmer \& Stoel-Gammon, } \\
\text { 2003) }\end{array}$ & 24 \\
\hline Speech Intelligibility & Beginner's Intelligibility Test & 60,84 \\
\hline
\end{tabular}




\begin{tabular}{|c|c|c|}
\hline DOMAINS ASSESSED: & MEASUREMENT INSTRUMENTS: & $\begin{array}{l}\text { AGE AT TEST } \\
\text { (months) }\end{array}$ \\
\hline \multicolumn{3}{|l|}{ ACADEMIC MEASURES } \\
\hline Phonological Processing \& Memory & $\begin{array}{l}\text { Comprehensive Test of Phonological } \\
\text { Processing (CTOPP) }\end{array}$ & $60,84,108$ \\
\hline $\begin{array}{l}\text { Phonological Awareness \& Print } \\
\text { Knowledge }\end{array}$ & Test of Preschool Early Literacy (TOPEL) & 48 \\
\hline Print Knowledge & TOPEL & 60 \\
\hline Word Attack & $\begin{array}{l}\text { Woodcock Reading Mastery Test-R (WRMT- } \\
\text { R) Word Attack }\end{array}$ & 72,96 \\
\hline Word Recognition & WRMT-R Word Identification & 72,96 \\
\hline Reading Comprehension & WRMT-R Reading Comprehension & 72,96 \\
\hline Spelling & $\begin{array}{l}\text { Weschler Individual Achievement Test } \\
\text { (WIAT)-II-A }\end{array}$ & 84,108 \\
\hline Math Reasoning & WIAT-II-A & 84,108 \\
\hline \multicolumn{3}{|c|}{$\begin{array}{l}\text { HEARING FUNCTION, AUDIBIITY \& } \\
\text { SPEECH PERCEPTION }\end{array}$} \\
\hline \multirow[t]{4}{*}{ Audiologic Evaluation } & History, Audiogram (VRA) + Tymps & Every visit \\
\hline & History, Audiogram (CPA) + Tymps & Every visit \\
\hline & History, Audiogram (Conventional) + Tymps & Every visit \\
\hline & Electroacoustic Analysis 60/90 Curves & Every visit \\
\hline Hearing Aid Function & Aided Speech Intelligibility Index (Verifit SII) & Every visit \\
\hline Audibility & Hearing Aid Checklist & Every visit \\
\hline Hearing Aid Use & Little Ears Questionnaire & $12,18,24$ \\
\hline \multirow[t]{7}{*}{ Speech Perception } & $\begin{array}{l}\text { Parent's Evaluation of Aural/Oral Performance } \\
\text { of Children (PEACH) }\end{array}$ & $\begin{array}{l}\text { 18, } 24 \text { (depending } \\
\text { on Little Ears score) }\end{array}$ \\
\hline & Early Speech Perception (ESP) lo-verbal & 24 \\
\hline & ESP & 24,36 \\
\hline & Phonetically Balanced Kindergarten (PBK) & 60,72 \\
\hline & $\begin{array}{l}\text { Computer-Assisted Speech Perception } \\
\text { Assessment (CASPA) }\end{array}$ & $84,96,108$ \\
\hline & $\begin{array}{l}\text { Multisyllable Lexical Neighborhood Test } \\
\text { (MLNT) \& Lexical Neighborhood Test (LNT) }\end{array}$ & 48 \\
\hline & Speech Spatial Qualities (SSQ) - revised & $48,72,96$ \\
\hline \multicolumn{3}{|l|}{$\begin{array}{l}\text { PSYCHOSOCIAL, BEHAVIORAL \& } \\
\text { FAMILY MEASURES }\end{array}$} \\
\hline \multirow[t]{5}{*}{ Cognitive Skills } & $\begin{array}{l}\text { Weschler Preschool \& Primary Scale of } \\
\text { Intelligence (WPPSI) }\end{array}$ & 48 \\
\hline & $\begin{array}{l}\text { Weschler Abbreviated Scale of Intelligence } \\
\text { (WASI) }\end{array}$ & 72,96 \\
\hline & Head to Toes Task & 72 \\
\hline & Vineland Adaptive Behavior Scales & $12,24,36,48$ \\
\hline & Friendship Interview & 72,96 \\
\hline Social Skills & Child Behavior Checklists (CBCL) & $24,48,72,96$ \\
\hline \multirow[t]{2}{*}{ Behavior } & Teacher Report Forms (TRF) & $48,72,96,108$ \\
\hline & Adult Perceptions II & 60 \\
\hline
\end{tabular}




\begin{tabular}{|c|c|c|}
\hline DOMAINS ASSESSED: & MEASUREMENT INSTRUMENTS: & $\begin{array}{l}\text { AGE AT TEST } \\
\text { (months) }\end{array}$ \\
\hline Parenting and Discipline & $\begin{array}{l}\text { Family Activities Checklist \& Parent Issues } \\
\text { Checklist }\end{array}$ & $48,72,96$ \\
\hline Family Activities & Infant Behavior Questionnaire & 12 \\
\hline \multirow[t]{3}{*}{ Child Temperament Early } & Childhood Behavior Questionnaire & 36 \\
\hline & $\begin{array}{l}\text { Children's Behavior Questionnaire - short } \\
\text { version }\end{array}$ & 48,72 \\
\hline & $\begin{array}{l}\text { Social Competence \& Behavior Evaluation } \\
\text { Scale }\end{array}$ & $60,84,108$ \\
\hline \multirow[t]{4}{*}{ School Behaviors (teacher report) } & Teacher Predictions of Peer Nominations & 84,108 \\
\hline & Direct and Indirect Aggression Scale - Teacher & 84,108 \\
\hline & Direct and Indirect Aggression Scale - Parent & 84,108 \\
\hline & $\begin{array}{l}\text { Screening Identification For Targeting } \\
\text { Educational Risk } \\
\text { (SIFTER - preschool \& school age) }\end{array}$ & $36,48,60,72,84,96$ \\
\hline \multicolumn{3}{|l|}{$\begin{array}{l}\text { FAMILY BACKGROUND \& } \\
\text { INTERVENTION MEASURES }\end{array}$} \\
\hline \multirow[t]{4}{*}{ Intervention Program Measures } & $\begin{array}{l}\text { OCHL Service Provider Survey (SPS)- } \\
\text { Audiology }\end{array}$ & Every visit \\
\hline & OCHL SPS 0 to 3 years & Each visit $6-35 \mathrm{~m}$ \\
\hline & OCHL SPS Preschool & Each visit $35-59 \mathrm{~m}$ \\
\hline & OCHL SPS School-Age & Each visit $60 \mathrm{~m}+$ \\
\hline Family Background \& Satisfaction & OCHL Family Interview & $\begin{array}{l}6 \text { months after } \\
\text { every visit }\end{array}$ \\
\hline Family Quality of Life & Beach Center Family Survey & $24,48,72,96$ \\
\hline
\end{tabular}




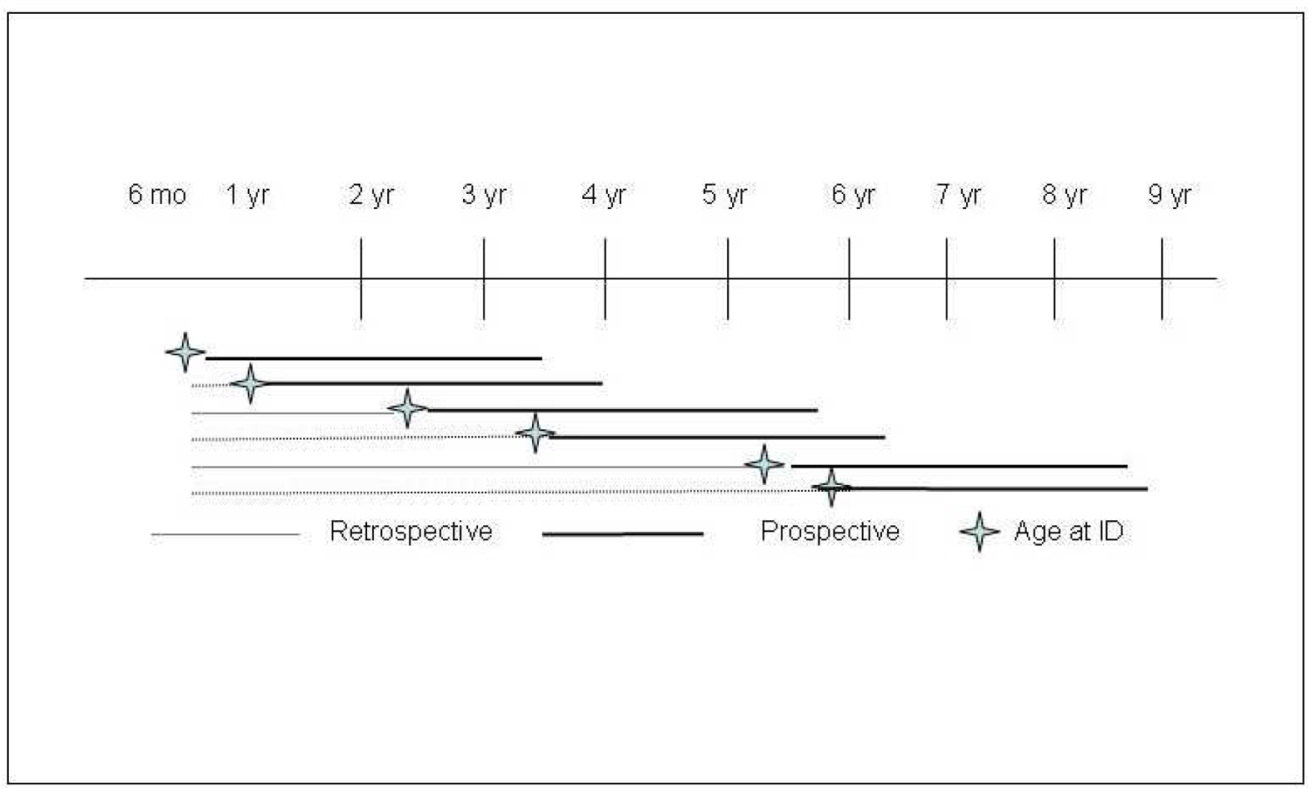

Figure 1.

Model of the accelerated longitudinal design used in the OCHL study. Vertical bars represent the age points at which data are obtained; stars indicate the age at which children are entered into the study (regardless of age at identification). 


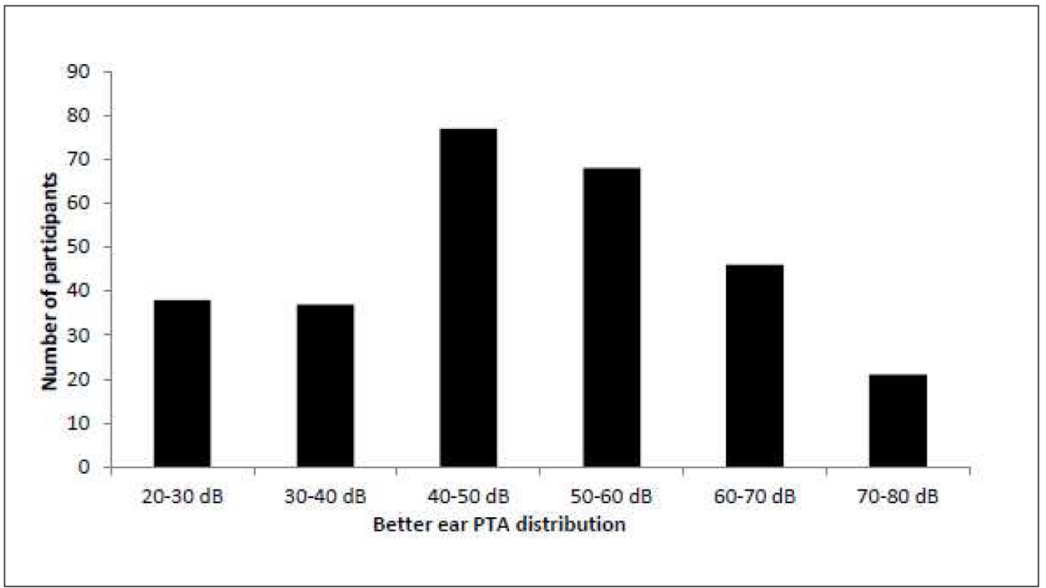

Figure 2.

Distribution of severity of hearing loss (better-ear pure tone average in $\mathrm{dB} \mathrm{HL}$ ) for all OCHL participants recruited to date 


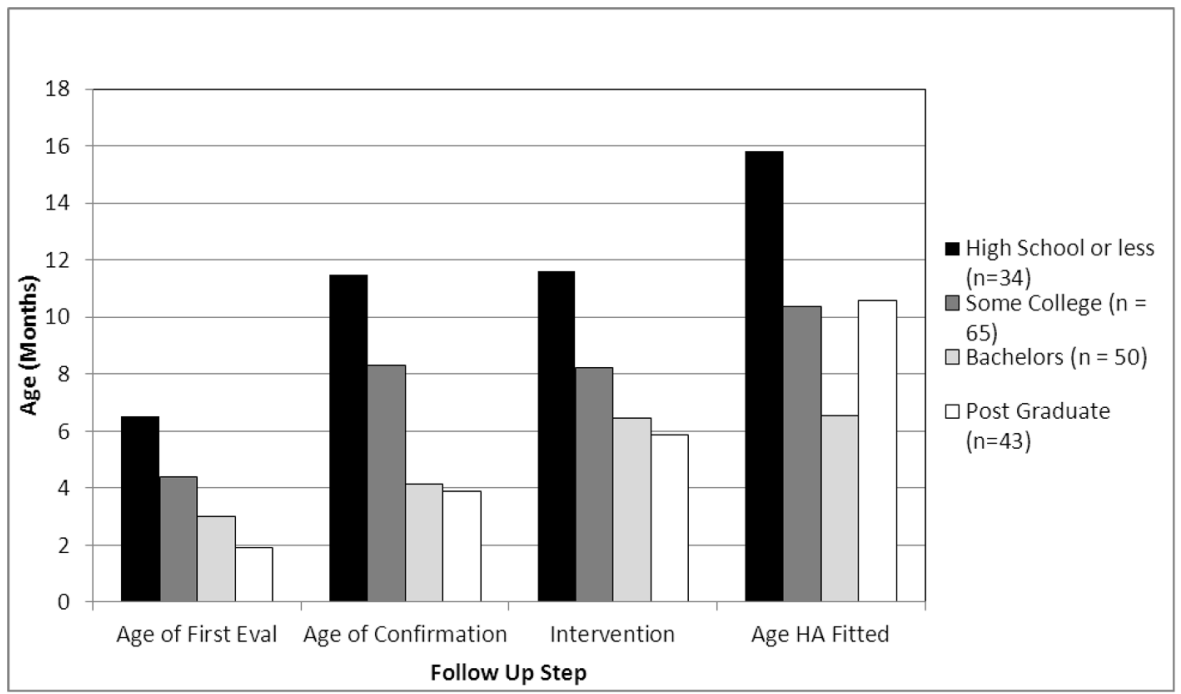

Figure 3.

Mean ages of first diagnostic audiologic evaluation $(\mathrm{p}=0.0123)$, confirmation of hearing loss $(\mathrm{p}=0.0013)$, hearing aid (HA) fit $(\mathrm{p}=0.0445)$ and entry into early intervention (EI) (NS) by mother's education for 193 children who did not pass the newborn hearing screen. 


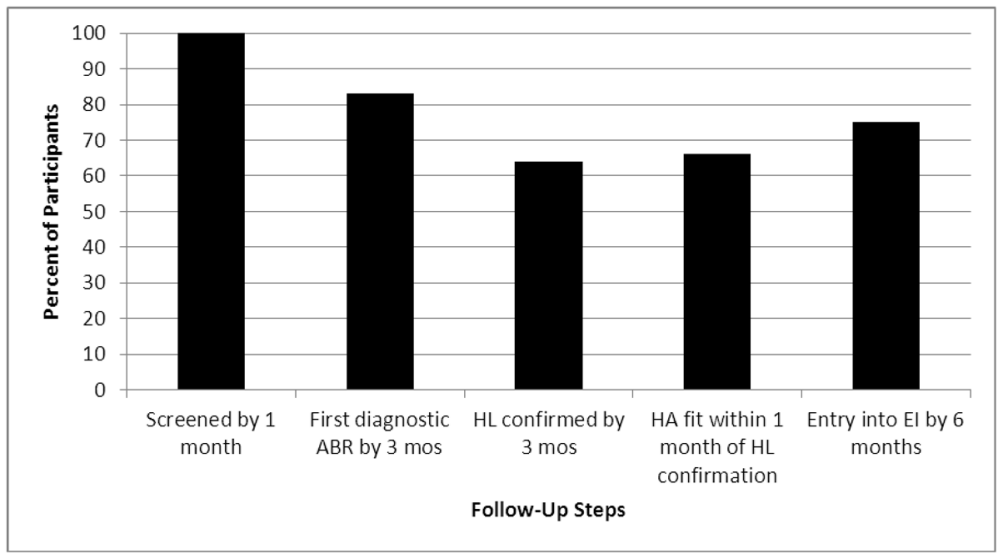

Figure 4.

Percentage of subjects meeting 1-3-6 goals for 193 children who did not pass newborn hearing screen (NHS). 


\section{Table 1}

Demographic characteristics of all OCHL participants with HL and mean and range of ages (in months) of JCIH benchmarks for subgroup who did not pass the NHS

\begin{tabular}{|c|c|c|c|}
\hline & & Full OCHL group (n=292) & Subgroup $(n=193)$ \\
\hline \multirow[t]{2}{*}{ Gender } & $\mathrm{F}$ & $134(45.9 \%)$ & $90(45.0 \%)$ \\
\hline & M & $158(54.1 \%)$ & $103(53.4 \%)$ \\
\hline \multirow[t]{3}{*}{ Research Site } & Iowa & $86(29.5 \%)$ & $57(29.5 \%)$ \\
\hline & Nebraska & $107(36.6 \%)$ & $68(35.2 \%)$ \\
\hline & North Carolina & $99(33.9 \%)$ & $68(35.2 \%)$ \\
\hline \multirow[t]{10}{*}{ Self-identified Race } & White & $223(76.4 \%)$ & $151(78.2 \%)$ \\
\hline & Black & $19(6.5 \%)$ & $12(6.2 \%)$ \\
\hline & Hispanic & $10(3.4 \%)$ & $5(2.6 \%)$ \\
\hline & Indian & $1(.3 \%)$ & $1(.5 \%)$ \\
\hline & Asian & $5(1.7 \%)$ & $4(2.1 \%)$ \\
\hline & Pacific & $1(.34 \%)$ & $1(.5 \%)$ \\
\hline & Multi-racial & $14(4.8 \%)$ & $11(5.7 \%)$ \\
\hline & Other & $5(1.7 \%)$ & $5(2.6 \%)$ \\
\hline & Refused & $2(.7 \%)$ & $1(.5 \%)$ \\
\hline & Blank & $12(4.1 \%)$ & $2(1.0 \%)$ \\
\hline \multirow[t]{3}{*}{ JCIH benchmarks } & Mean age of HL confirmation (range) & & $6.78(0.5-70)$ \\
\hline & Mean age of HA fit in months (range) & & $10.33(1.5-72)$ \\
\hline & Mean age of entry into EI (range) & & $\begin{array}{l}7.74(0-57) \\
\text { Not reported for all }\end{array}$ \\
\hline
\end{tabular}


Table 2

Reasons provided by parents for delays in confirmation of HL and follow-up in children who did not pass the NHS

\begin{tabular}{|c|c|}
\hline Reasons for delay of more than 2 months between identification of HL (failed NHS) and first dx ABR & $\mathbf{N}$ \\
\hline Multiple re-screenings & 33 \\
\hline Family chose to wait before scheduling diagnostic test & 4 \\
\hline $\begin{array}{l}\text { Delayed because family was assured that the failed screening was likely caused by something other than permanent hearing loss (e.g. } \\
\text { middle ear fluid after c-section delivery). }\end{array}$ & 2 \\
\hline Delayed due to treatment of middle ear problems & 4 \\
\hline Family was not told to get a diagnostic ABR & 3 \\
\hline Difficulty getting an appointment quickly & 6 \\
\hline Other & 15 \\
\hline \multicolumn{2}{|l|}{ Reasons for delays of more than 3 months between first diagnostic test and confirmation of hearing loss } \\
\hline Multiple retesting & 15 \\
\hline Recurrent middle ear infections & 1 \\
\hline \multicolumn{2}{|l|}{ Other: } \\
\hline Initial ABR was normal or near normal & 5 \\
\hline Fluctuating hearing loss due to Enlarged Vestibular Aqueduct & 1 \\
\hline Unclear about reason & 1 \\
\hline \multicolumn{2}{|l|}{ Reasons for delay of more than 1 month between confirmation and hearing aid fitting } \\
\hline Delay in obtaining appointment for medical clearance for hearing aids & 2 \\
\hline Delay in obtaining approval for insurance or other $3^{\text {rd }}$ party funding for hearing aids & 4 \\
\hline Hearing aids were not initially recommended & 11 \\
\hline Difficulty obtaining clinic appointment for hearing aid fitting & 10 \\
\hline Family decided not to proceed with hearing aid fitting right away & 12 \\
\hline Child had other medical conditions that prevented follow up for hearing aid fitting & 2 \\
\hline Child had recurrent ear infections or other middle ear problems & 2 \\
\hline Other & 19 \\
\hline Reasons for delay between confirmation of hearing loss and entry into early intervention & $\mathrm{N}$ \\
\hline Family believed infant was too young for intervention & 3 \\
\hline Delay by service provider in starting services & 2 \\
\hline Family did not believe there was a hearing loss & 1 \\
\hline Unilateral hearing loss progressed to bilateral and then services started & 2 \\
\hline Delayed due to testing for other medical issues & 1 \\
\hline
\end{tabular}

